International Journal of Engineering \& Technology, $7(2.6)(2018) 206-212$
International Journal of Engineering \& Technology
Website: www.sciencepubco.com/index.php/IJET
Research Paper

\title{
A Survey on flow meters based on application
}

\author{
Sakthivel S R ${ }^{1}$, Sudarshan $K^{2}$, Balaji Venkateswaran $\mathbf{V}^{3 *}$ \\ ${ }^{1,2,3}$ Dept. of Electrical, Power and Energy, University of Petroleum and Energy Studies \\ *Corresponding author E-mail: b.venkateswaran@ddn.upes.ac.in
}

\begin{abstract}
Flow meters are those instruments that are used to measure the flow of fluid. The term fluid is a quite general because it involves both liquids and gases, so technically flow meters are those instruments that are used to measure the flow of liquids and gases. There have been numerous classifications for fluids, based on viscosity, operating pressure and temperature and even based on the type of measurement, whether it is done in a conduit or out in the open. The main objective of this paper is to develop a reference table based on the various applications of flow meters.
\end{abstract}

\section{Introduction}

Fluids are being used everywhere from manufacturing industries to assembly from aerospace and automobiles to transmission industries. All of these industries use one kind of fluid or the other but the one common thing about all these industries is that they have to measure the amount of fluids that are being used. And that is where the flow meters play a very important role. In addition to this the main reason why both gases and liquids are classified under fluids is because of their behavior; both liquids and gases behave the same under macroscopic conditions.

Flow meters as per the name can be defined as those instruments that are used to measure the flow of fluid. Now based on the industry these flow meters can be used to measure the quantity of flow of fluids in both conduits and be used to measure the amount of fluid flow out in the open, like in the case of the flow meters that are being used to measure the flow velocity of air in aircrafts or to measure the flow velocity of water in rivers or any other water bodies.

The type of flow meter that is being used for a particular application will depencd largely on the type of fluid that is being passed through and that is what this paper is intended to do [4][6][7]; classify the flow meters based on the application or in other words the type of fluid being passed through.

\section{Classification of Fluids}

Fluids in general can be classified in to four types,

- Ideal fluids,

- Newtonian fluids,

- Non- Newtonian fluids and

- Ideal plastic fluid

Ideal fluids are defined as those fluids which are incompressible in nature and because of this these fluids will have zero viscosity[8][9]. A fluid with such properties can never exist because every fluid will some kind of viscosity. Newtonian fluids are those fluids which obey the Newton's law of viscosity, which is given by $\tau=\mu$ * $d u / d y$. Such fluids are called as real fluids and the best example for them is water, air, mercury etc. On the other hand, non- Newtonian fluids are those fluids who do not obey the Newton's law of viscosity. The best examples for these are paints, polymers etc. Ideal plastic fluids are those fluids, which have a definite yield stress and a constant linear relation to $\tau$ in the viscosity law. Printers ink and other thixotropic substance are the examples of real plastic fluids. The relationship between velocity gradient and stress is shown in figure 1 .

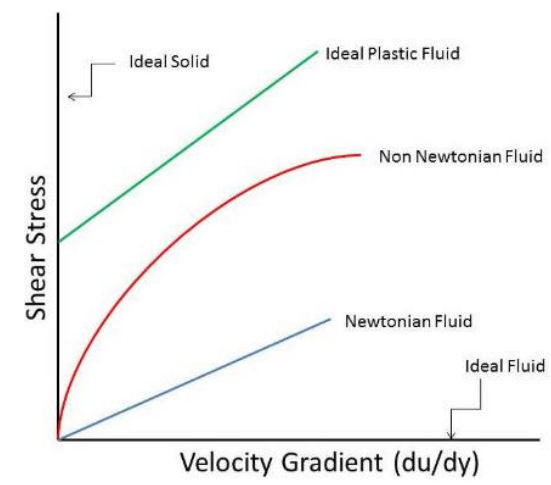

Fig. 1: Relationship between stress and velocity gradient

The other means for classifying a fluid is based on the properties[10]. When we talk of properties that are related to fluids we can classify the fluids in to a large number of categories making it tiresome so in this paper we are going to classify the fluids based on those properties that are very important to industries.

The various properties that we can use to classify fluids are as follows,

- Density,

- Viscosity,

- Electrical conductivity, 
- Contaminants,

- $\quad$ [11]Flow range,

- Fluid temperature,

- Fluid pressure and in some cases even

- Pressure loss.

As you can see from above, the properties of each fluid area varying and because of this varying nature it gives us opportunity to classify the fluids based on them.

But because this paper mainly focuses on the application side, the description to the above properties is not being given in detail. The various ways to classify the fluids based on the application is shown in figure 2.

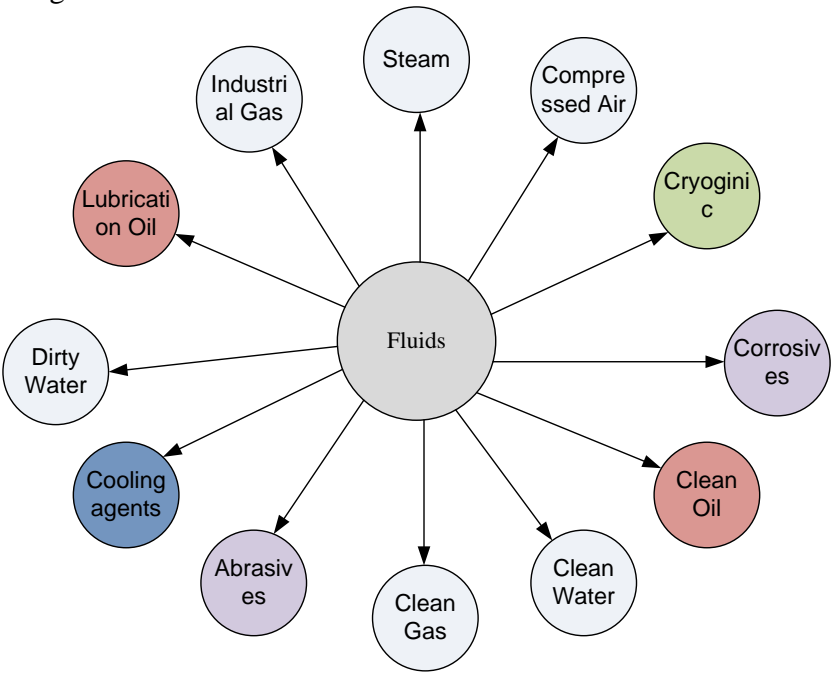

Fig. 2: Classification of fluids based on its application

Cooling water is used for any equipment from I.C engine to power plants and also in industries or equipments where the need to cool the equipments very vital[12][13]. This will lead to the use of different type of fluids. Cooling water is one the fluid. The main advantage of cooling water is that it is easily available, not hazardous and reliable. The main method of cooling is convective heat transfer. Properties of fluid such as density and its corresponding factors are subjected to change with varying pressure, temperature. Water is subjected to phase change; it stays in liquid form from $1^{\circ} \mathrm{C}$ to $100^{\circ} \mathrm{C}$. At an atmospheric pressure which is a standard value of 1.01325 bar, provided it is under normal atmospheric pressure on the sea level at $0^{\circ} \mathrm{C}$. But at the same time, the density in $\mathrm{kg} / \mathrm{m} 3$ at $0{ }^{\circ} \mathrm{C}$ will be around 999.82 and for $100^{\circ} \mathrm{C}$ it will be around 958.05 . Thus, the operating conditions will play a major role in deciding the working parameters of the cooling water. The same is shown in Table 1.

Table 1: Properties of Cooling water

\begin{tabular}{|c|c|c|c|c|}
\hline & $\begin{array}{c}\text { Density } \\
(\mathbf{k g} / \mathbf{m 3})\end{array}$ & $\begin{array}{c}\text { Pres- } \\
\text { sure } \\
(\mathbf{a t m})\end{array}$ & $\begin{array}{c}\text { Specific heat } \\
(\mathbf{K j} / \mathbf{K g . K})\end{array}$ & $\begin{array}{c}\text { Dynamic viscos- } \\
\text { ity (kg/m.s) }\end{array}$ \\
\hline $\mathbf{0}^{\circ} \mathbf{C}$ & 999.82 & 1 & 4.217 & 0.001792 \\
\hline $\mathbf{1 0 0}^{\circ} \mathbf{C}$ & 958.05 & 1 & 4.216 & 0.000282 \\
\hline
\end{tabular}

Lubricant is any substance that reduces friction and wear at the interface of two materials[14]. The lubricant at interface reduces the adhesive friction by lowering the shear strength at the interface[15]. Based on the shear strength of lubricant or molecular state, lubricants are classified in four categories,

- Gaseous lubricant,

- Liquid lubricant,

- Semi- solid/ paste like lubricant and

- Solid lubricant

The machinery which are used in power plants or the components of a nuclear power reactor are all equipments that are used in extreme conditions. In these conditions the conventionally used lubricants cannot be used so under these circumstances the solid lubricants are used. [15][16]. So under these circumstances, the lubricant is usually used either in its powdered form or in the form of a paste and at times even in the form of a metallic film.

Semi solid lubricants which are in the form of pastes are mostly used in industries which have machinery that run at low speeds [11], which means the semi solid lubricant is mostly used in places which have bearings that run at low speeds. In addition to that, these semi solid lubricants can be used in equipments where the operating temperature is more than $300^{\circ} \mathrm{C}[15]$. The best example for this is grease. Grease can be used in almost all the different kinds of machinery[15][14].

In addition to the above mentioned types, there is another type of lubricant which is used under special conditions. A condition is considered special when we require a lubricant that is economical ( cost wise), that is resistant to radioactive radiation or when the operating temperatures ranges are extremely high (range (200 to $+650^{\circ} \mathrm{C}$ ). Under these circumstances we use a bonded lubricant.

Gases are used as lubricants in gas-lubricated bearings[17][18] $(14,222)$ which operate in the aerodynamic (at high speeds 10,000 to 600,000 r.p.m.) or aerostatic regimes at temperatures from 15 to 800 "C or more, where liquid lubricants would freeze or decompose, in hostile environments (e.g., radiation, etc.), where there is danger of contamination and other difficult or unusual situations. the advantages of gas lubrication include the low viscosities of gases, which increase with tempe-rature, low pressure loss, low coefficients of friction, small frictional heat generation, absence of local hot-spots, 'the omnipresence of the lubricants on the surfaces and the absence of sealing, clogging and contamination problems.

Industrial gases are actually a generalized term. Under this term we can define a large number of products that are gaseous at room temperature and pressure.

Oxygen, hydrogen, nitrogen, carbon dioxide and in addition to that even noble gases such as argon, neon, xenon, and krypton are the most commonly used industrial gases. In the above mix of gases, there are a few that are pressurized and converted to liquids in order to increase the ease of storage and transportation. At even lower temperatures these liquids can turn to a solid. Dry ice, a solid form of carbon dioxide, is a common example Compressed air (CA) used for many purposes [19][20] has wide applications as shown in figure 3 .

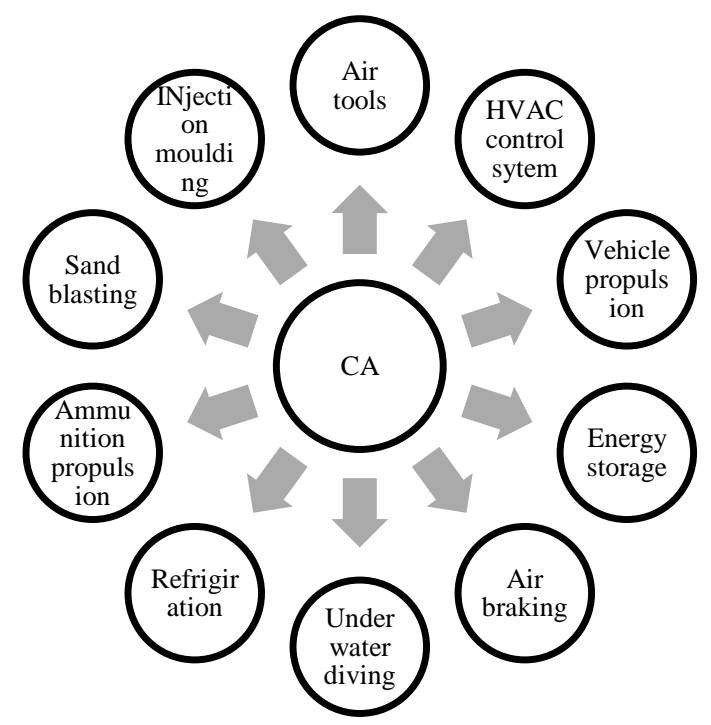

Fig. 3: Applications of compressed air (CA)

Oil has been one of the most important sources of energy since time it was found out. It is being used in almost all the different kinds of sectors from automobile to thermal power plants, from lubrication to power generation and transmission sector. The problem with this 
level of usage is that it is has the ability to release quite some amount of green house gases and in addition to that the amount of oil reserves in the world are being depleted at a much faster rate than expected. All of this has led to usage of flow meters in this sector too. The problems with the flow meters that are being used in this sector is that, they operating conditions have to be kept in mind at all times; these operating conditions are mostly the physical parameters of the oil, viscosity, temperature, pressure etc.

As the name suggests, corrosives are materials that have the ability to damage the surface they are being exposed to. These corrosives are of two types, acid and base. The corrosive acids best example is $\mathrm{HCl}, \mathrm{H}_{2} \mathrm{SO}_{4}$ and the corrosive bases best example are $\mathrm{NH}_{4} \mathrm{OH}$, $\mathrm{KOH}, \mathrm{NaOH}$. The problem with these corrosives is that, a few of them are actually explosive in nature and have the ability to catch fire very easily.

Clean gas can be anything starting from natural gas, hydrogen, producer gas and even oxygen used in cylinder tanks. But the main feature of all these gas is that they are filtered of all the impurities present in them. So, once the gas is filtered out the amount of gas that is coming out will have to be measured in order to determine the efficiency of the cleaning process. This measurement is once again done with the help of flow meters.

Abrasives are can be defined as those substances that are used in industries which have functions that are related to grinding, polishing, cleaning, of any solid material. This is mainly achieved by the rubbing action of the abrasive on the surface of a material[21]. There are some characteristics that are used to classify a material as an abrasive and they are as follows hardness, toughness and even grain size and shape [21].

Clean water just like oil is used in many industries starting from automobile to thermal power plants. All of these industries have to keep a constant check on the amount of water that is being used in the process and that's where the flow meters come into play. In the case of thermal power plants the amount of water that is being sent in to the boiler or the amount of water that is being sent in to the condenser all have to be monitored. Thus making flow meters, one of the most important of equipments in the entire thermal power plant.

Cryogenics is study of the properties of materials when the it is reduced to extremely low temperatures. For reducing the temperature of the body, liquefied gases like liq. Nitrogen or liquid helium is used[22]. In order to pump such kinds of liquids the normal pumps that we use for water or oil pumping cannot be used instead a special kind of pump called cryogenic transfer pumps are used. Cryogenic fluids also find themselves being used in nuclear resonance imaging, electric power transmission, frozen food industry, blood banks, manufacturing process and even in rockets.

Dirty gas, dirty water and steam are pretty much like flue stack gases and the boiler blow down water and the steam quantity that is being fed in to the turbines. These three are very vital in a power plant because they will determine the overall efficiency of the power plant and that is why the flow meters play a very important role.

There are various kinds of flow meters that can be used for each of the applications mentioned above and a few of them are discussed in the next section.

\section{Classification of Flow Meters}

In the following sub-sections, various flow meters based on its application is described and the same is tabulated in Table 2.

\subsection{Cooling water}

There are two flow meters that can be used to measure rhe flow of cooling water and they are as follow,

\section{Vane type flow meter.}

The vortex shedding flow meter works on the basis that when a fluid is passed by an object, oscillations may occur. Vortex fluidic flow meters are flow meters that generate oscillations due to flow[23]. Vortex flow metersuses a bluff body obstruction, whereas the other fluidic flow meters include designs on the working of the Coanda effect and vortex precession. The basic concept that increases in flow increases the oscillation frequency. Now with a help of a sensor, it will detect the number of oscillations that are generated and with the help. Vortex flow meters which uses a bluff/ dummy body that is $20 \%$ of itsID of the pipe which is located at symmetrically traverse to the stream which is flowing to create downstream vortices of the shedder[24]. The frequency of the vortex generation is directly proportional to the fluid flow rate. The nominal pressure drop which is associated with these meters for water service is around $300 \mathrm{mbar}$ at $5 \mathrm{~m} / \mathrm{sec}$ [25]. On the other hand, the flow meters that use coanda effect contains two feedback passages that alternately bring fluid back to the flow meter inlet so as to alternately direct the flow to attach itself to one of the two internal "walls" of the flow meter[24][25]. The frequency of the flow alternation between the feedback passages is directly proportional to the flow rate of the fluid. The vortex precession fluid meters are insensitive to hydraulic disruptions in flow of fluids. Vane type flow meters are a type of variable area flow meter which measures the flow by allowing the stream to change the opening of a moving internal part within the flow meter[26]. So, when the flow force is high the internal part will be pushed further and when the flow is low the corresponding action will take place. In order to bring the vane back to the original position these meters have a spring fixed to them thus forcing the vane to move either forward or backwards based on the intensity of the flow and then back to the original position[4][25][27]. The problem related to such spring loaded device is that it will lose its tension after a period of time, so the spring might have to recalibrated after a period of time. In addition to being used as a flow measurement device for cooling water flow measurement these flow meters are used to measure the flow of lubricating oil.

\subsection{Industrial Gas}

To measure the flow of industrial gas like Carbon Dioxide, Air, Nitrogen, Hydrogen, Helium or Argon, the laminar flow meters are used. They are a type of differential pressure flow meters. Bernoulli's equation principle is used for differential pressure working which measure the fluid flow through a pipe [28]. This type of flow meters introduce an effect which creates a pressure drop in the pipe. When the flow increases, more pressure drop is created. This equation states that the pressure drop across the constriction will be proportional to the square of the flow rate. On the other hand for a laminar flow, the pressure drop will be linear to the flow rate thus making it very useful for reading the low end of the scale and in addition to that, it will also increase the "turn down" from 10:1 to 100:1 [25]. The flow is calculated by measuring differential pressure and we have to factor in the pressure and the temperature readings in order to obtain an even more accurate result.

\subsection{Compressed Air}

According to various reports and officials there are four main elements that are required in an industry- man, machine, money and compressed air. In addition to having this value of importance in an industry, compressed air is also a costly affair and that is why the amount of compressed air that is being consumed should be measured at all times and that is where flow meters come into play. 
Table 2: Flow meter classification and its properties

\begin{tabular}{|c|c|c|c|c|c|c|c|c|c|}
\hline $\begin{array}{l}\text { Flow } \\
\text { meter }\end{array}$ & Subtypes & Applications & Flow range & $\begin{array}{l}\text { Operat- } \\
\text { ing tem- } \\
\text { perature }\end{array}$ & $\begin{array}{l}\text { Viscos- } \\
\text { ity }\end{array}$ & $\begin{array}{l}\text { Turndown } \\
\text { Ratio }\end{array}$ & $\begin{array}{l}\text { Operat- } \\
\text { ing } \\
\text { Pres- } \\
\text { sure }\end{array}$ & $\begin{array}{l}\text { Accu- } \\
\text { racy }\end{array}$ & $\begin{array}{l}\text { Pres- } \\
\text { sure } \\
\text { Drop }\end{array}$ \\
\hline $\begin{array}{l}\text { Lami- } \\
\text { nar flow } \\
\text { type }\end{array}$ & - & Clean Gas & $0-120 \mathrm{~m} 3 / \mathrm{h}$ & NA & NA & 100:01:00 & NA & NA & NA \\
\hline \multirow[t]{2}{*}{$\begin{array}{l}\text { Ther- } \\
\text { mal } \\
\text { Flow } \\
\text { Meter }\end{array}$} & $\begin{array}{l}\text { capillary ther- } \\
\text { mal mass } \\
\text { flowmeter } \\
\text { (CTMF) }\end{array}$ & $\begin{array}{l}\text { Compressed Air, } \\
\text { Clean Gas }\end{array}$ & 0.1 and $0.5 \mathrm{~kg} / \mathrm{h}$ & 0 to $65^{\circ} \mathrm{C}$ & $100 \mathrm{cP}$ & $15: 01$ & 400 bar & $0.5-1 \%$ & NA \\
\hline & $\begin{array}{l}\text { In-line ther- } \\
\text { mal mass } \\
\text { flowmeters } \\
\text { (ITMFs) }\end{array}$ & $\begin{array}{l}\text { Compressed Air, } \\
\text { Clean Gas }\end{array}$ & $300-8,000 \mathrm{~kg} / \mathrm{h}$ & $\begin{array}{l}-50 \text { to } \\
300^{\circ} \mathrm{C}\end{array}$ & NA & $800: 01: 00$ & NA & NA & $\begin{array}{l}10 \\
\text { mbar }\end{array}$ \\
\hline $\begin{array}{l}\text { Turbine } \\
\text { flow me- } \\
\text { ter }\end{array}$ & - & $\begin{array}{l}\text { Clean Oil, Clean } \\
\text { Water, }\end{array}$ & $\begin{array}{l}0.03 \mathrm{~m} 3 / \mathrm{h} \text { to } \\
7,000 \mathrm{~m} 3 / \mathrm{h}\end{array}$ & $\begin{array}{l}-265^{\circ} \mathrm{C} \text { to } \\
+310^{\circ} \mathrm{C}\end{array}$ & NA & $30: 01: 00$ & $\begin{array}{l}240 \text { to } \\
400 \text { bar }\end{array}$ & $\begin{array}{l} \pm 0.25 \% \\
\text { to } \pm 0.5 \%\end{array}$ & $\begin{array}{l}14 \\
\text { mbar }\end{array}$ \\
\hline \multirow{6}{*}{$\begin{array}{l}\text { Positive } \\
\text { dis- } \\
\text { place- } \\
\text { ment }\end{array}$} & $\begin{array}{l}\text { Nutating Disc } \\
\text { Meter }\end{array}$ & Clean Water & $10-1001 / \mathrm{min}$ & $\begin{array}{l}\text { up to } \\
80^{\circ} \mathrm{C} \\
\end{array}$ & $\begin{array}{l}1,000 \\
\mathrm{mPa} \\
\end{array}$ & NA & $\begin{array}{l}\text { min of } \\
0.1 \text { bar }\end{array}$ & $1 \%$ & NA \\
\hline & $\begin{array}{l}\text { Oval Gear } \\
\text { Meter }\end{array}$ & $\begin{array}{l}\text { adhesives and pol- } \\
\text { ymers }\end{array}$ & up to $1,200 \mathrm{~m} 3 / \mathrm{h}$ & $\begin{array}{l}\text { up to } \\
290^{\circ} \mathrm{C}\end{array}$ & $\begin{array}{l}0.4-20 \\
\text { cP }\end{array}$ & $10: 01$ & NA & NA & $\begin{array}{l}0.5-1 \\
\text { bar }\end{array}$ \\
\hline & $\begin{array}{l}\text { Sliding Vane } \\
\text { Meters }\end{array}$ & $\begin{array}{l}\text { Cooling water, } \\
\text { Clean oil, orro- } \\
\text { sives, Clean Water }\end{array}$ & & $\begin{array}{l}-25 \text { to } \\
100^{\circ} \mathrm{C}\end{array}$ & NA & NA & $\begin{array}{l}\text { up to } 10 \\
\text { bar }\end{array}$ & NA & $\begin{array}{l}70- \\
100 \\
\mathrm{kPa} \\
\end{array}$ \\
\hline & $\begin{array}{l}\text { Helical Rotor } \\
\text { Meter }\end{array}$ & lubrication & $\begin{array}{l}\text { maximum of } 13 \\
\mathrm{~m} 3 / \mathrm{h}\end{array}$ & $\begin{array}{l}\text { up to } \\
290^{\circ} \mathrm{C}\end{array}$ & $\begin{array}{l}\text { up to } \\
106 \mathrm{cP}\end{array}$ & NA & $\begin{array}{l}\text { up to } \\
230 \text { bar, }\end{array}$ & NA & NA \\
\hline & $\begin{array}{l}\text { Reciprocating } \\
\text { Piston Meters }\end{array}$ & $\begin{array}{l}\text { gasoline } \\
\text { pumps ,hydraulic } \\
\text { test stands }\end{array}$ & up to $33 \mathrm{~m} 3 / \mathrm{h}$ & NA & $\begin{array}{l}\text { up to } \\
30,000 \\
\mathrm{cP}\end{array}$ & $1,800: 1$ & NA & \pm 0.5 & NA \\
\hline & $\begin{array}{l}\text { Precision } \\
\text { Gear (Spur } \\
\text { Gear) Flow- } \\
\text { meters }\end{array}$ & Clean oil & $\begin{array}{l}\mathrm{s} \text { high as } 1,000 \\
1 / \mathrm{min}\end{array}$ & $\begin{array}{l}-30 \text { to } \\
150^{\circ} \mathrm{C}\end{array}$ & NA & NA & $\begin{array}{l}\text { up to } \\
300 \text { bar }\end{array}$ & NA & NA \\
\hline \multirow[t]{2}{*}{$\begin{array}{l}\text { Corio- } \\
\text { liss flow }\end{array}$} & $\begin{array}{l}\text { Straight tube } \\
\text { type }\end{array}$ & $\begin{array}{l}\text { Dirty Gas, } \\
\text { Crypgenic, Dirty } \\
\text { water, Abbrasives }\end{array}$ & to $2,000 \mathrm{t} / \mathrm{h}$ & $\begin{array}{l}-240^{\circ} \mathrm{C} \text { to } \\
+427^{\circ} \mathrm{C}\end{array}$ & NA & $20: 1$ to $100: 1$ & $\begin{array}{l}\text { up to } \\
\text { about } \\
390 \text { bar }\end{array}$ & NA & NA \\
\hline & $\begin{array}{l}\text { Single-tube } \\
\text { meters }\end{array}$ & $\begin{array}{l}\text { Dirty Gas, } \\
\text { Crypgenic, Dirty } \\
\text { water, Abbrasives }\end{array}$ & $\begin{array}{l}\text { up to } 180,000 \\
\mathrm{~kg} / \mathrm{h}\end{array}$ & $\begin{array}{l}-25^{\circ} \mathrm{C} \text { to } \\
130^{\circ} \mathrm{C}\end{array}$ & NA & NA & NA & $\begin{array}{l} \pm 0.05 \% \\
\text { to } \pm 0.3 \%\end{array}$ & NA \\
\hline \multirow{2}{*}{$\begin{array}{l}\text { Differ- } \\
\text { ential } \\
\text { pressure }\end{array}$} & Orifice & Industrial gas & & $\begin{array}{l}\text { Upto } 800 \\
\operatorname{deg}^{\circ} \mathrm{C}\end{array}$ & NA & NA & $\begin{array}{l}\text { Upto } \\
400 \text { bar* }\end{array}$ & $\begin{array}{l} \pm 0.5 \text { to } \pm \\
3.0\end{array}$ & NA \\
\hline & $\begin{array}{l}\text { Venturi meter } \\
\text { and nozzle } \\
\text { flow meter }\end{array}$ & Industrial gas & & NA & NA & NA & NA & $\begin{array}{l} \pm 0.5 \text { to } \pm \\
3.0\end{array}$ & NA \\
\hline $\begin{array}{l}\text { Varia- } \\
\text { ble area } \\
\text { meter }\end{array}$ & Rotameter & $\begin{array}{l}\text { Compressd Air, } \\
\text { clean Oil and cor- } \\
\text { rosives }\end{array}$ & $\begin{array}{l}\text { Liquid }-0.001 \\
1 / \mathrm{min} \text { to } 100 \\
\mathrm{~m} 3 / \mathrm{h} \text { gases }-0.1 \\
1 / \mathrm{min} \text { to } 1,800 \\
\mathrm{~m} 3 / \mathrm{h}\end{array}$ & $\begin{array}{l}-180 \text { to } \\
400^{\circ} \mathrm{C}\end{array}$ & NA & $10: 01$ & NA & $\begin{array}{l}1.6 \% \text { to } \\
5 \%\end{array}$ & NA \\
\hline Vortex & - & $\begin{array}{l}\text { Cooling Water, } \\
\text { corosives, Seam, } \\
\text { Clean water Dirty } \\
\text { Gas }\end{array}$ & $\begin{array}{l}\text { liquid - up to } 9 \\
\mathrm{~m} / \mathrm{s} \text {, gas- up to } \\
75 \mathrm{~m} / \mathrm{s}\end{array}$ & $\begin{array}{l}-200^{\circ} \text { to } \\
\text { over } \\
400^{\circ} \mathrm{C}\end{array}$ & NA & $\begin{array}{l}20: 1 \text { for gas } \\
\text { and steam } \\
\text { 10:1 for liq- } \\
\text { uids }\end{array}$ & $\begin{array}{l}-200^{\circ} \text { to } \\
\text { over } \\
400^{\circ} \mathrm{C}\end{array}$ & NA & $\begin{array}{l}\text { up to } \\
30 \mathrm{cP}\end{array}$ \\
\hline $\begin{array}{l}\text { Ultra- } \\
\text { sonic }\end{array}$ & - & $\begin{array}{l}\text { Dirty Water, } \\
\text { Clean water, Ab- } \\
\text { brasives }\end{array}$ & $\begin{array}{l}0.03 \mathrm{~m} / \mathrm{s} \text { to } 10 \\
\mathrm{~m} / \mathrm{s}\end{array}$ & $\begin{array}{l}-200^{\circ} \mathrm{C} \text { to } \\
+250^{\circ} \mathrm{C}\end{array}$ & NA & NA & NA & NA & NA \\
\hline
\end{tabular}


There are two different flow meters that can be used to measure the flow of compressed air,

\section{Thermal flow meters}

\section{Float style (variable area) flow meter}

In a thermal flow meter the thermal properties of the fluid are used to measure the fluid flowing through a pipe or a duct. In a typical thermal flow meter, the sensor measures the amount of heat. Some of it is lost to the continuously flowing fluid but the quantity of the heat lost from the sensor depends on the design of the sensor and the thermal and other properties of the fluid[29]. So, as the fluid flow increases, more amount of heat will be lost. The amount of heat lost is measured by using sensors for temperature measurement. The transmitter uses the value of heat as input and temperature measurements for determining the quantity of the fluid flow. Most thermal flow meters are used to measure amount of gas flows[4].

The thermal properties of the fluid may vary with different pressure or temperature, however these variations are typically negligible in most applications. For some of these applications where the various thermal properties of the flowing fluid are known which stays constant during normal operation, this flow meters is used to measure the fluid flow as there is no affect of temperature or pressure in the fluid[29][30]. One of the most important parameter that has to be factored in, in order to use thermal flow meters to measure the flow is the property and the composition of the fluid This is because the flow meter will have to be calibrated according to that specific fluid in order to obtain proper accuracy.

As mentioned above, a variable flow meter will measure the flow of fluid by moving an internal part. So, when the flow increases the internal moving part will move accordingly. The float style flow meter measures the fluid flow in a transparent vertical metering tube which is balanced by the downward weight of the float with the upward force caused by the flowing fluid[25]. Like the vane flow meter, the float type flow meter too is Spring loaded. These are easy to read as the metering device is transparent metering tubes have markings, which is calibrated which relates the height of the flow float with the fluid flow.

\subsection{Clean Oil}

In order to measure the flow of clean oil, there are 3 main types of flow meters that are used and they are as follows,

1. Vane type flow meter,

2. Turbine flow meter and

3. Float style (variable area) flow meter

The vane type flow meter and the float style (variable area) flow meter have the same functioning as mentioned above.

It is logical that when the term turbine is used anywhere we can safely assume that mechanical energy is used in the mix somehow or the other. The turbine flow meter too works by exploiting the fluidic flow energy and extracting it and converting it to a rotating motion. This rotating motion is achieved with the help of a rotor.[31]. Typically, this rotor is placed in the direction of flow. Thus as the rotor converts the fluid's flow energy into rotating energy by rotating on a bearing we will be able to get the flows characteristics. The rotor's spin will increase proportionally to the velocity of the flow and the output of the spin can be calculated by the use of magnets in the bearings. These magnets will help generate an output which can then be measured by the help of electrical circuits[32]. The problem with these flow meters is that they can wear and become inaccurate when they are used to measure the flow of non- lubricating fluids.

\subsection{Corrosives}

Corrosives are quite difficult to measure because as the name suggests they are quite corrosive in nature. But there are few types of flow meters that can be used to measure the flow and they are as follows,
1. Vortex shedding,
2. Vane style,
3. Float style (variable area) flow meter
4. Paddle wheel and
5. Magnetic flow meter

The first three have already been discussed above.

The paddle flow meter is very similar to that of the turbine flow meter. It has the same working principle as the turbine flow meter[4]. It too is placed in the direction of the fluid flow and it also converts the flow of the fluid to a rotating motion and the with the help of rotor rotating in a magnetic field we will be able to find out the fluids flow characteristics[25]. When a magnetic flow meter is used to determine the flow of liquid in a pipe we can be sure that the fluid is conducting in nature. These flow meters work on the principle of Faraday's law Electro-magnetic Induction which states that a voltage will be generated that is proportional to the movement of the flowing liquid[33]. In this case, a magnetic field will be generated externally and then it's channeled into the liquid flowing through the pipe. This will result in a voltage signal that can be easily sensed by set of the electrodes that located on the flow tube walls[34]. So when the fluid moves faster, the voltage generated too will increase, correspondingly. The electronic transmitter processes the voltage signal to determine liquid flow. The turndown of magnetic flow meters is around 20:1 or better without sacrificing accuracy[25].

\subsection{Clean Gas}

Clean gas can be measured by any of the following types of flow meters,

1. Laminar flow meter,

2. Thermal flow meter and

3. Float style (variable area) flow meter

All the above mentioned flow meters have been discussed above and they have the same working principle as mentioned above.

\subsection{Abrasives}

The two main types of flow meters that are used to measure the flow of abrasives are,

1. Ultrasonic flow meter and

2. Coriolis mass flow meters

The ultrasonic flow meter uses sound waves to find the fluid velocity for a fluid flow through a pipe. when there is no flow the time taken for the upstream and downstream is the same. On the other hand, when there is flow of fluid in the pipe, the frequency of the reflected wave will be different. This is because of phenomena called as Doppler Effect[36]. The faster the fluid flows, the frequency shift will increases linearly. The two main elements of this flow meter are the transmitter and the receiver, the transmitter processes signals from the transmitted wave and its reflections to determine the flow rate and the receiver does the function its name 
is depicted for. Another type of ultrasonic flow meter is the transit time ultrasonic flow meters where the signal is sent and received by between transducers for the upstream and downstream in fluid flow of a pipe[25].when there is no flow the time taken for the upstream and downstream is the same. when there is fluid the time taken for upstream will be less compared to downstream [37]. As the fluid flow increases the speed the time take difference will be more. The Coriolis mass flow meters measures the force caused by acceleration by mass moving toward the center of rotation[38]. This is felt when riding a merry-go-round, where the person moving towards the center will have to "lean into" the rotation to maintain proper balance. The "tube where the fluid flows through is subjected to vibration; the twist of the tubes is proportional to the quantity of the fluid passing through the tube. Sensors and also a Coriolis meter transmitter are used to measure the amount of twist generated to form a linear flow signal[25][39].

\subsection{Clean Water}

The advantage with measuring the flow of clean water is that, a number of instruments can be used to measure it. A few of them are listed below,

1. Vortex shedding flow meter

2. Vane style flow meter

3. Variable area flow meter

4. Paddle wheel flow meter

5. Turbine flow meter

6. Ultrasonic flow meter

\subsection{Cryogenic}

The two commonly used flow meters to measure the flow of cryogenic fluids are,

1. Coriolis mass flow meters and

2. Differential pressure flow meters

All the above mentioned flow meters have already been discussed above and they have the same principle for working as mentioned above.

\subsection{Dirty Gas}

The dirty gas can be measured by

1. Vortex shedding flow meter,

2. Differential pressure flow meter and

3. Coriolis mass flow meters

All of which have been discussed earlier. In addition to that, they have the same working principle as mentioned above.

\subsection{Dirty Water}

Dirty water can be measured by the following equipments,

1. Magnetic flow meter,

2. Ultrasonic flow meter and

3. Coriolis mass flow meters

All of which have been discussed earlier. In addition to that, they have the same working principle as mentioned above.

\subsection{Steam}

As mentioned above steam is an important commodity especially in the thermal power plants.
The flow meters used to measure them are as follows,

1. Vortex shedding flow meter

2. Differential pressure flow meter.

All of which have been discussed earlier. In addition to that, they have the same working principle as mentioned above.

\subsection{Lubrication}

For measuring the amount of lubricant that is being used in a particular machining the vane type flow meter is used. The description and the working principle is the same as mentioned above.

\section{Conclusion}

In this paper, the fluids are classified based on its application, which gives an insight to choose the particular meter for a specific fluid. In addition, the properties of all the flow meters available in the market is elaborated this makes the user to select the flow meter with respect to a particular application the corresponding flow meter can be chosen with ease. The parameters considered here are Sub- types ( if any ) for each flow meter, Application, Flow range, Operating temperature, Viscosity, Turndown ratio, Operating pressure, Accuracy and Pressure drop.

\section{References}

[1] J. Larwill, "MEANS FOR COOLING SOLID PARTICULATE MATER ALS WITH FLUIDS," 1968.

[2] P. E. A. Focarino, "MEDICAL APPARATUS FORWARMING PATIENT FLUIDS," no. 19, 1985.

[3] P. Mishra and S. N. Gupta, "Momentum Transfer in Curved Pipes. 2. Non-Newtonian Fluids," Ind. Eng. Chem. Process Des. Dev., vol. 18, no. 1, pp. 137-142, 1979.

[4] R. C. Baker, Flow Measurement Handbook. 2000

[5] S. K. Jaiswal, S. Yadav, and R. Agarwal, "Design and development of a novel water flow measurement system," Meas. J. Int. Meas. Confed., vol. 105, no. April, pp. 120-129, 2017.

[6] J. McWilliams, "Review of Airflow Measurement Techniques Jennifer McWilliams Energy Performance of Buildings Group Environmental Energy Technologies Division Lawrence Berkeley National Laboratory Berkeley, CA 94720," Pulse, p. 116, 2002.

[7] M. T. H. E. Flow, P. O. F. Yield, and S. Fluids, "Measuring the Flow," Victoria, pp. 47-88, 1992.

[8] "Classification of Fluids," 2014. [Online]. Available: http://www.mechanical-engineeringassignment.com/classification-of-fluids

[9] W. N. Bond and D. A. Newton, "LXXXII. Bubbles, drops, and Stokes' law. (Paper 2)," London, Edinburgh, Dublin Philos. Mag. J. Sci., vol. 5, no. 30, pp. 794-800, 1928.

[10] "HOW TO SELECT A FLOW METER." [Online]. Available: https://www.keyence.com/ss/products/process/flowknowledge/i ntroduction/how_to.jsp.

[11] Z. L. Cheng and X. X. Qin, "Study on friction performance of graphene-based semi-solid grease," Chinese Chem. Lett., vol. 25, no. 9, pp. 1305-1307, 2014.

[12] F. R. of G. Dietmar Peter, Hemmingen, "COOLING ARRANGEMENT FOR AN AUTOMOTIVE VEHICLE, ESPECIALLY A PASSENGER CAR," 1973.

[13] Y. Magara, "INDUSTRIAL WATER," WATER Qual. Stand., vol. I, no. Industrial Water.

[14] G. J. Johnston, R. Wayte, and H. A. Spikes, "The measurement and study of very thin lubricant films in concentrated contacts," Tribol. Trans., vol. 34, no. 2, pp. 187-194, 1991.

[15] C. Donnet and A. Erdemir, "Historical developments and new trends in tribological and solid lubricant coatings," Surf. Coatings Technol., vol. 180-181, pp. 76-84, 2004.

[16] C. Donnet and a Erdemir, "Solid Lubricant Coatings: Recent Developments and Future Trends," Tribol. Lett., vol. 17, no. 3, pp. 389-397, 2004.

[17] Geoffrey Beardmore, "GAS-LUBRICATED BEARINGS," 1990. 
[18] S. Richard C, Elwell, "GAS LUBRICATED BEARNGS," 1967.

[19] "Compressed air," 2018. [Online]. Available: https://en.wikipedia.org/wiki/Compressed_air\#Uses_of_compre ssed_air.

[20] R. Saidur, N. A. Rahim, and M. Hasanuzzaman, "A review on compressed-air energy use and energy savings," Renew. Sustain. Energy Rev., vol. 14, no. 4, pp. 1135-1153, 2010.

[21] R. Ritesh, G. R. Chandra, I. D. M. Association, S. Sanjiv, and D. Ravelino, "Physical \& chemical properties of Abrasive Grain," 2010.

[22] "Industrial Gases," Engineering 360. [Online]. Available: https://www.globalspec.com/learnmore/materials_chemicals_ad hesives/industrial_specialty_gases/industrial_specialty_gases.

[23] C. (US); Gregg Pulley, Berthoud and I. (US) Vaibhav Kulkarni, Columbus, "VORTEX SHEDDING FLOW METER," 2012.

[24] H. Zhang, Y. Huang, and Z. Sun, "A study of mass flow rate measurement based on the vortex shedding principle," Flow Meas. Instrum., vol. 17, no. 1, pp. 29-38, 2006.

[25] R. C. Baker and Cambridge University Press., Flow Measurement Handbook: Industrial Designs, Operating Principles, Performance, and Applications. 2016.

[26] Emory frank Stove, "VANETYPE FLOW METER," 1967.

[27] Thomas J. Scarpa, "FLOWMETER," no. 19, 1973.

[28] N. T. Nguyen, "Micromachined flow sensors - a review," Flow Meas. Instrum., vol. 8, no. 1, pp. 7-16, 1997.

[29] M. Farzaneh-Gord, S. Parvizi, A. Arabkoohsar, L. Machado, and R. N. N. Koury, "Potential use of capillary tube thermal mass flow meters to measure residential natural gas consumption," $J$. Nat. Gas Sci. Eng., vol. 22, pp. 540-550, 2015.

[30] M. Viswanathan, A. Kandaswamy, S. K. Sreekala, and K. V. Sajna, "Development, modeling and certain investigations on thermal mass flow meters," Flow Meas. Instrum., vol. 12, no. 56, pp. 353-360, 2002.

[31] M. W. Johnson and S. Farroll, "Development of a turbine meter for two-phase flow measurement in vertical pipes," Flow Meas. Instrum., vol. 6, no. 4, pp. 279-282, 1995.

[32] P. A. Mark, M. W. Johnson, J. L. Sproston, and B. C. Millington, "The turbine meter applied to void fraction determination in twophase flow," Flow Meas. Instrum., vol. 1, no. 5, pp. 246-252, 1990.

[33] X.-Z. Zhang, "Calculation and measurement of the magnetic field in a large diameter electromagnetic flow meter.," ISA Trans., vol. 42, no. 2, pp. 167-170, 2003.

[34] J. A. Virbalis, "Errors in electromagnetic flow meter with magnetic particles," Flow Meas. Instrum., vol. 12, no. 4, pp. 275-282, 2001.

[35] K. Tawackolian, O. Büker, J. Hogendoorn, and T. Lederer, "Calibration of an ultrasonic flow meter for hot water," Flow Meas. Instrum., vol. 30, pp. 166-173, 2013.

[36] C. Carlander and J. Delsing, "Installation effects on an ultrasonic flow meter with implications for self diagnostics," Flow Meas. Instrum., vol. 11, no. 2, pp. 109-122, 2000.

[37] J. S. Battye, "Acoustic considerations effecting the design of demodulators for the ultrasonic correlation flow meter," Sensors Actuators, A Phys., vol. 88, no. 1, pp. 29-40, 2001.

[38] M. Anklin, W. Drahm, and A. Rieder, "Coriolis mass flowmeters: Overview of the current state of the art and latest research," Flow Meas. Instrum., vol. 17, no. 6, pp. 317-323, 2006.

[39] M. Henry, "Book Review: Flow Measurement Handbook (Second Edition) Roger C. Baker," Flow Meas. Instrum., vol. 55 pp. 73-74, 2017. 